\title{
Dose and side effects of sublingual misoprostol for treatment of postpartum hemorrhage: what difference do they make?
}

\author{
Wilfrido León ${ }^{1}$, Jill Durocher ${ }^{2 *}$, Gustavo Barrera ${ }^{1}$, Ernesto Pinto ${ }^{2}$ and Beverly Winikoff ${ }^{2}$
}

\begin{abstract}
Background: Shivering and fever are common side effects of misoprostol. An unexpectedly high rate of fever above $40^{\circ} \mathrm{C}$ was documented among Ecuadorian women given treatment with $800 \mathrm{mcg}$ of sublingual misoprostol to manage postpartum hemorrhage (PPH) (36\%). Much lower rates have been reported elsewhere (0-9\%).

Methods: From February to July 2010, an open-label pilot study was conducted in Quito, Ecuador to determine whether a lower dose--600mcg sublingual misoprostol--would result in a lower incidence of high fever $\left(\geq 40^{\circ} \mathrm{C}\right)$. Rates of shivering and fever with $600 \mathrm{mcg}$ sublingual regimen were compared to previously documented rates in Ecuador following PPH treatment with $800 \mathrm{mcg}$ sublingual misoprostol.

Results: The $600 \mathrm{mcg}$ dose resulted in a $55 \%$ lower rate of high fever compared with the $800 \mathrm{mcg}$ regimen (8/50; $16 \%$ vs. 58/163; 36\%; relative risk $0.4595 \% \mathrm{Cl} 0.23-0.88$ ). Only one woman had severe shivering following the $600 \mathrm{mcg}$ dose compared with 19 women in the $800 \mathrm{mcg}$ cohort ( $2 \%$ vs. $12 \%$; relative risk $0.17(0.02-1.25)$ ). No cases of delirium/altered sensorium were reported with the $600 \mathrm{mcg}$ dose and women's assessment of severity/tolerability of shivering and fever was better with the lower dose.

Conclusions: $600 \mathrm{mcg}$ sublingual misoprostol was found to decrease the occurrence of high fever among Ecuadorian women when given to treat PPH. This study however was not powered to examine the efficacy of this treatment regimen and cannot be recommended at this time. Future research is needed to confirm whether other populations, outside of Quito, Ecuador, experience unusually high rates of elevated body temperature following sublingual administration of misoprostol for treatment of PPH. If indeed similar trends are found elsewhere, larger trials to confirm the efficacy of lower dosages may be justified.
\end{abstract}

Trial Registration: Clinical trials.gov, Registry No. NCT01080846

Keywords: misoprostol, postpartum hemorrhage, PPH, fever

\section{Background}

Misoprostol, a prostaglandin E1 derivative, is a safe and effective alternative for managing postpartum hemorrhage $(\mathrm{PPH})$ due to uterine atony $[1,2]$ however, concerns still remain about its side effects profile [3]. The most common side effects associated with the postpartum administration of misoprostol for $\mathrm{PPH}$ are shivering and fever [4]. Rates of shivering and fever have been shown to be higher following oral and sublingual routes of administration compared with rectal and

\footnotetext{
* Correspondence: jdurocher@gynuity.org

${ }^{2}$ Gynuity Health Projects, New York, NY, USA

Full list of author information is available at the end of the article
}

vaginal routes [5,6]. Nevertheless, the sublingual administration of misoprostol, due to its rapid onset of action, has been identified as being the most useful application for controlling postpartum bleeding [7].

In several studies, misoprostol has been associated with fever greater than $40.0^{\circ} \mathrm{C}\left(104^{\circ} \mathrm{F}\right)$ when used to manage PPH $[1,2,8-13]$. Multi-center studies testing an $800 \mathrm{mcg}$ regimen of sublingual misoprostol for treatment of $\mathrm{PPH}$ reported a higher-than-expected rate of fever above $40^{\circ} \mathrm{C}$ in one of nine sites (Ecuador: $36 \%$ ), whereas much lower rates were recorded in the other eight sites, ranging from 0 to $9 \%[1,2,14]$. All of these cases in all sites were transient and resolved within several hours

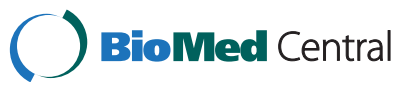


and without complication. Nonetheless, it is unclear why some women developed high body temperature while others did not and why nearly all of the high fevers occurred in Ecuador. Environmental factors, clinical practices and patient characteristics that could possibly contribute to the increased rate of high fevers among Ecuadorian women have been explored, and no patterns or associations have been identified [14]. These unanswered questions pose challenges for providers and policymakers interested in introducing $800 \mathrm{mcg}$ sublingual misoprostol as a treatment option in Ecuador. Currently, no data support other routes of administration or lower doses of misoprostol for first-line PPH care. Although there is some evidence that a lower dose would reduce the occurrence of side effects $[3,15,16]$, the effectiveness of a lower dose as first-line PPH treatment has not yet been studied.

To understand better the relationship between misoprostol dose and occurrence of fever, a pilot study was conducted in Quito, Ecuador using a lower dose of sublingual misoprostol for the treatment of $\mathrm{PPH}$. The study aimed to confirm whether a $600 \mathrm{mcg}$ dose would reduce the incidence of elevated body temperature $\left(\geq 40^{\circ} \mathrm{C}\right)$ associated with misoprostol. In this manuscript, the side effect profile of the $600 \mathrm{mcg}$ sublingual regimen is compared to previously documented rates of shivering and fever using $800 \mathrm{mcg}$ sublingual misoprostol in Ecuador. The results from this study help shed light on whether lower doses of misoprostol might be considered and add to the discussion of the possible trade-offs among efficacy, safety (side effects) and acceptability.

\section{Methods}

From February to July 2010, we conducted an open-label study at Hospital Gineco-Obstétrico Isidro Ayora, a large public tertiary care maternity hospital in Quito, Ecuador, to test a $600 \mathrm{mcg}$ dose of sublingual misoprostol for the treatment of PPH. The study sought to evaluate the side effect profile and acceptability of sublingual misoprostol $(600 \mathrm{mcg})$ as a first-line treatment among women delivering vaginally with suspected uterine atony. The study was approved by the hospital ethics committee and is registered with Clinical trials.gov NCT01080846.

Upon presentation to the labor ward, women were screened for eligibility and informed about the study. Informed consent was obtained for all eligible women and documented via signature or thumb print. Women who had a known allergy to prostaglandin or had a planned cesarean-section were excluded from participation. Consenting women were administered 10 IU oxytocin intramuscularly during the third stage of labor as routine practice at the hospital. Postpartum blood loss was measured following vaginal delivery using a polyurethane receptacle with a calibrated funnel (Brasss-V Drapes ${ }^{\circledR}$,
Excellent Fixable Drapes, India). Socio-demographic and delivery characteristics, pre-delivery hemoglobin and blood loss at one-hour postpartum were documented for all women, regardless of whether they later received treatment for PPH. Women who underwent a cesarean-section or whose postpartum bleeding was not suspected to be due to atonic uterus were later excluded from the study.

Women diagnosed with excessive bleeding that the clinical care team deemed would benefit from uterotonic therapy were enrolled. The treatment regimen consisted of three $200 \mathrm{mcg}$ pills of misoprostol given sublingually (under the tongue). Data were collected on the side effects detected by providers or reported by women following treatment administration. Delivery attendants rated the severity (mild, moderate or severe) of any side effect noted and recorded any treatment given to manage it. Body temperature was measured systematically at 60-minutes and 90-minutes for all women given study treatment using an oral mercury thermometer. If the woman's body temperature measured $\geq 40.0^{\circ} \mathrm{C}$ at any time, temperature measures were monitored and recorded every half-hour until the fever subsided (below $38.0^{\circ} \mathrm{C}$ ). Management practices for reducing fever included removing blankets from the patient, applying cool compresses, administering oral acetaminophen, and ensuring adequate hydration by mouth or intravenously. All other side effects necessitating treatment were managed according to hospital's clinical protocol.

Prior to discharge from the hospital, delivery attendants interviewed women about the acceptability of side effects following treatment. Phone follow-up interviews were conducted by study staff one-week after hospital discharge with all women who had experienced high fever to confirm that they had no recurring side effects or health problems that might be related to their treatment.

Women requiring additional care beyond first-line treatment with misoprostol to control postpartum bleeding were provided standard care. Although this study was not powered to confirm the efficacy of the $600 \mathrm{mcg}$ sublingual regimen, measures of treatment success were documented to help generate hypotheses for future research addressing the efficacy of the lower dose regimen.

An independent advisory committee was established to review reports of adverse events, provide advice on risk management, and review study findings. Close monitoring of reported side effects continued throughout the study. If at any time the total number of cases of high fever exceeded 15, a stopping rule required that the investigators consult the advisory committee to seek their advice on study continuation and whether a further dose reduction was necessary.

We hypothesized that significantly fewer women would experience high fever following a $600 \mathrm{mcg}$ regimen of sublingual misoprostol, compared to a previously 
documented rate of $36 \%$ following $800 \mathrm{mcg}$ in Quito, Ecuador [2,14]. Incidence of shivering and fever are related and dose- and route- dependent [3-7]. Previous research on use of misoprostol for PPH has suggested that fever rates are generally halved when misoprostol regimens eliminate one tablet of $200 \mathrm{mcg}[3,15]$. Thus, it was hypothesized that a lower dose of misoprostol would reduce the rate of high fever by $50 \%$ in this setting. To detect a one-sided difference of $50 \%$ or less, with $80 \%$ power at the alpha $=0.05$ level, a maximum of 75 cases of PPH was required.

Data were entered and analyzed using the Statistical Package for the Social Sciences, version 15.0 (SPSS, Chicago, IL, USA). Descriptive statistics were calculated for maternal side effects and their severity. Elevated body temperature measuring $\geq 40.0^{\circ} \mathrm{C}$ was classified as high fever regardless of its duration. The rate of high fever was then compared to documented rates following use of $800 \mathrm{mcg}$ sublingual misoprostol in the previous trial that was conducted at the same hospital in Ecuador $[2,14]$. Relative risk (RR) and 95\% confidence intervals were calculated as appropriate for comparisons between outcomes among Ecuadorian women treated with $600 \mathrm{mcg}$ and $800 \mathrm{mcg}$ in the present and previous studies, respectively. Importantly, when the previous trial on the $800 \mathrm{mcg}$ dose was conducted, systematic provision of oxytocin prophylaxis was not part of the hospital norms; whereas in the present study, administration of oxytocin prophylaxis is now routine. Thus, the comparisons take into account the two different clinical circumstances in which the treatments were offered $(600 \mathrm{mcg}$ sublingual misoprostol after oxytocin prophylaxis; $800 \mathrm{mcg}$ sublingual misoprostol with no previous prophylaxis).

\section{Results}

A total of 764 consenting women were enrolled, of whom 727 had their blood loss measured following vaginal delivery using a calibrated receptacle. Thirty-seven women underwent cesarean-section and were excluded. Among those women who were screened for PPH, 6.9\% (50/727) were diagnosed with PPH due to atonic uterus and were administered treatment with $600 \mathrm{mcg}$ of sublingual misoprostol. The median blood loss at the time uterotonic treatment was initiated was $850 \mathrm{ml}$ (IQR 750, 1050). Active bleeding was controlled within 20 minutes with misoprostol alone for $82.0 \%$ (41/50) of women. Additional uterotonics were administered to nine women, and one woman received a blood transfusion. The median total blood loss for women treated with $600 \mathrm{mcg}$ sublingual misoprostol was $1000 \mathrm{ml}$ and the proportion of women with a change in hemoglobin from pre- to post-delivery of $2 \mathrm{~g} / \mathrm{dL}$ or more was $63.3 \%(31 / 49)$.

Nearly all women given this regimen experienced shivering and fever (Table 1). The incidence of high fever
Table 1 Side effects reported by delivery attendants among Ecuadorian women given PPH treatment with sublingual misoprostol $(600 \mathrm{mcg}$ and $800 \mathrm{mcg})$ *

\begin{tabular}{llll}
\hline & $\begin{array}{l}\mathbf{6 0 0} \mathbf{~ m c g} \\
(\mathbf{n}=\mathbf{5 0})\end{array}$ & $\begin{array}{l}\mathbf{8 0 0} \mathbf{~ m c g} \\
(\mathbf{n}=\mathbf{1 6 3})\end{array}$ & RR 95\% Cl \\
\hline Any fever & $44(88.0)$ & $151(92.6)$ & $0.95(0.85-1.06)$ \\
$\geq 40.0^{\circ} \mathrm{C}$ & $8(16.0)$ & $58(35.6)$ & $0.45(0.23-0.88)$ \\
Any shivering & $48(96.0)$ & $146(89.6)$ & $1.07(0.99-1.16)$ \\
Severe shivering & $1(2.0)$ & $19(11.7)$ & $0.17(0.02-1.25)$ \\
Any fainting & $2(4.0)$ & $4(2.5)$ & $1.63(0.31-8.64)$ \\
Any nausea & $0(0.0)$ & $8(4.9)$ & - \\
Any vomiting & $0(0.0)$ & $8(4.9)$ & - \\
Any diarrhea & $0(0.0)$ & $2(1.2)$ & - \\
Any delirium or & $0(0.0)$ & $10(6.1)$ & -
\end{tabular}

altered sensorium

Any other side effect $\wedge \quad 1(2.0) \quad 10(6.1) \quad 0.33(0.04-2.48)$

* Values are given as $\mathrm{n}(\%)$ unless stated otherwise.

${ }^{\wedge} 600 \mathrm{mcg}$ dose -- headache (1); $800 \mathrm{mcg}$ dose -- headache (2), thirst (3), pain/ cramping (3), excessive sweating (1), Feel cold/teeth chattering (1).

(above $40.0^{\circ} \mathrm{C}$ ) was $16 \%(8 / 50)$ and the highest peak temperature recorded was $40.9^{\circ} \mathrm{C}$. Among those women who experienced high fever, average temperatures remained above 40 degrees for less than 1 hour. Only one woman had severe shivering and no cases of delirium or altered sensorium were reported. All other side effects were negligible (Table 1). Baseline characteristics, clinical practices and $\mathrm{PPH}$ outcomes (including blood loss measures, hemoglobin levels, and recourse to additional interventions) were similar among women with high fever and those without (data not shown).

Prior to discharge, women were asked to report any side effects experienced and rate their severity. Among those women confirming provider reports during their exit interview of having had fever, four women characterized the fever as severe or not tolerable $(4 / 31 ; 12.9 \%)$. Eighty-percent (40/50) of women deemed the side effect profile as overall acceptable, $14.0 \%(7 / 50)$ had neutral response to the question, and $6.0 \%$. (3/50) described their side effects as not acceptable.

Women with high fever were contacted by study staff one-week following hospital discharge to interview them about any recurring side effects. Six of the eight women who had high fever were contacted, three of whom reported experiencing mild fever since hospital discharge. The reports of mild fever were not deemed by the study team to require further care. No other problems or concerns were reported by women during their phone follow-up interview.

There were no maternal deaths, no hysterectomies, or other surgeries following first-line treatment with $600 \mathrm{mcg}$ sublingual misoprostol. All fifty women were reported to be in good condition upon discharge from the study. 


\section{Discussion}

Following treatment with $600 \mathrm{mcg}$ sublingual misoprostol for $\mathrm{PPH}$, the incidence of high fever $\left(\geq 40.0^{\circ} \mathrm{C}\right)$ was $55 \%$ lower in this study than that recorded in a previous study giving women $800 \mathrm{mcg}$ of sublingual misoprostol in Ecuador (relative risk 0.45 95\% CI 0.23-0.88) (Table 1). The lower dose did not reduce the overall incidence of shivering and fever following postpartum treatment with sublingual misoprostol in this setting. In both studies, approximately nine out of ten women experienced shivering and fever irrespective of the dose received (Table 1). Nevertheless, perceived tolerability/severity of fever was significantly improved following the lower treatment dose. Only four women treated with $600 \mathrm{mcg}$ characterized the fever as severe or not tolerable (4/31; $12.9 \%)$. In comparison, $43.6 \%(44 / 101)$ of women in the $800 \mathrm{mcg}$ study reporting fever in their exit interview described this side effect as severe or not tolerable (relative risk 0.30 95\% CI 0.12-0.76). There were no reports of delirium or altered sensorium among those treated with $600 \mathrm{mcg}$ sublingual misoprostol; whereas eleven $(11 / 163 ; 6.7 \%)$ women reported this effect when given $800 \mathrm{mcg}$ sublingual misoprostol to treat hemorrhage.

These results provide further evidence of the dosedependent nature of misoprostol-induced side effects. Shivering and fever were commonly experienced by Ecuadorian women following both the $600 \mathrm{mcg}$ and $800 \mathrm{mcg}$ doses studied, yet the intensity of these effects appears to be reduced with the lower dose. For instance, the lower dose was associated with a lower peak temperature $\left(40.9^{\circ} \mathrm{C}\right.$ vs. $41.8^{\circ} \mathrm{C}$ in the $800 \mathrm{mcg}$ study) and, on average, a 30-minute shorter duration of temperature above $40.0^{\circ} \mathrm{C}$, compared with those treated with $800 \mathrm{mcg}$ sublingual misoprostol in the previous study (Figure 1). Only one woman experienced severe shivering in the $600 \mathrm{mcg}$ cohort compared with 19 women treated with $800 \mathrm{mcg}$ given sublingually ( $2 \% \mathrm{vs}$. $12 \%$; relative risk $0.17(0.02-1.25)$ ) (Table 1). A similar pattern was noted in one study that compared the side effect profiles of $200 \mathrm{mcg}, 400 \mathrm{mcg}$, and $600 \mathrm{mcg}$ regimens of sublingual misoprostol for the management of PPH among Libyan women [17]. In all three treatment groups, the majority of women had shivering (75\%$100 \%)$ and fever $(83 \%-100 \%)$ confirmed by systematic temperature measurement, yet only $8 \%$ in the $200 \mathrm{mcg}$ and $400 \mathrm{mcg}$ groups had fever above $39.0^{\circ} \mathrm{C}$, compared with $45 \%$ given $600 \mathrm{mcg}$ sublingually. There were no cases of fever above $40.0^{\circ} \mathrm{C}$ in Libya [17].

Although the lower dose of sublingual misoprostol was associated with a reduction in the rate of high fever in Ecuador, the proportion of Ecuadorian women experiencing high fever (16\%) is considerably higher than rates documented in studies using the same regimen for $\mathrm{PPH}$ indications. In one large multi-country study, body temperature following adjunct $\mathrm{PPH}$ treatment with $600 \mathrm{mcg}$ of sublingual misoprostol was systematically measured, confirming a rate of high fever of 7\% (48/704) [13]. In Pakistan, a study of the adjunct use of $600 \mathrm{mcg}$ sublingual misoprostol for treatment of $\mathrm{PPH}$ documented a 3\% rate of high fever (1/29) [12]. Six other PPH prevention studies utilizing $600 \mathrm{mcg}$ sublingual misoprostol report no cases of fever above $40.0^{\circ} \mathrm{C}$ among a total of 835 women given this regimen [16-21]. Clinical practices and patient characteristics of Ecuadorian women treated with $600 \mathrm{mcg}$ sublingual misoprostol were analyzed to explore whether there were any patterns or

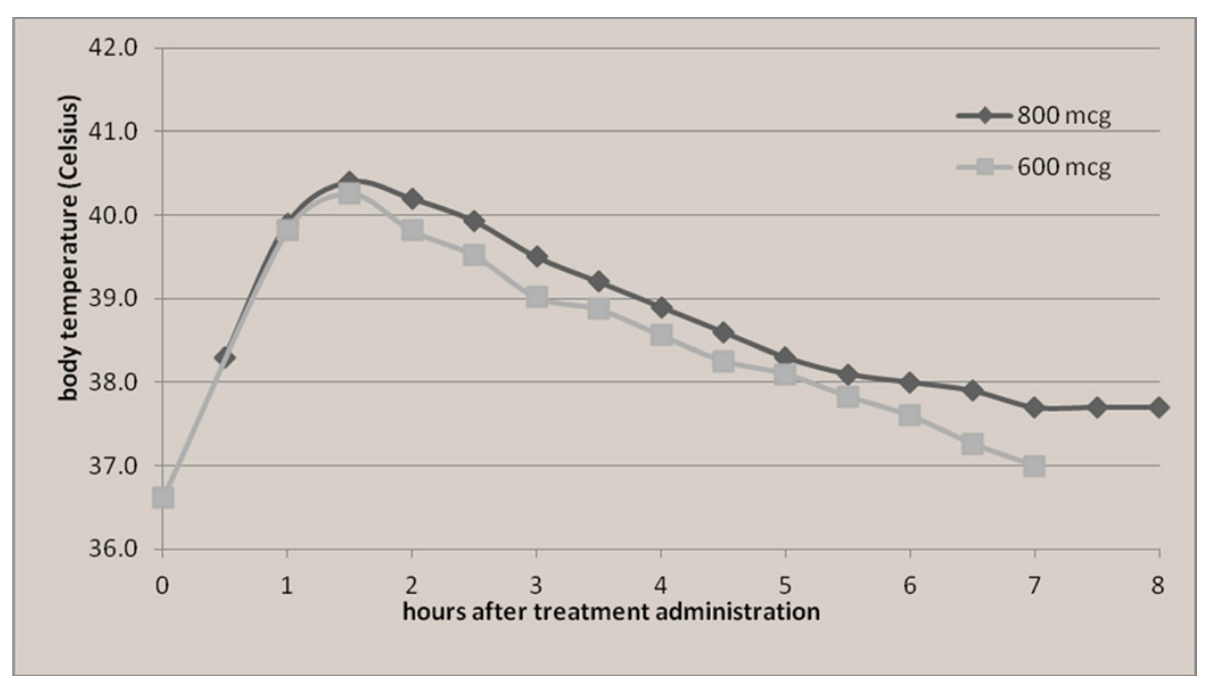

Figure 1 Average temperature trends for cases with high fever following $600 \mathrm{mcg}(n=8)$ and $800 \mathrm{mcg}(n=58)$ doses of misoprostol for PPH treatment. 
associations with the occurrence of high fever, and none were identified. Thus, we have hypothesized that the thermoregulatory response to misoprostol is based on genetic factors, which would explain the variable frequency of fever/high fever among different populations. Pharmaco-genetic analyses are underway to determine whether genetic variability in genes encoding enzymes responsible for metabolism and transport of misoprostol can explain why Ecuadorian women experience higher rates of elevated temperature (personal communication, Ana Alfirevic, The University of Liverpool).

The findings from this pilot study are limited due to the small sample size. The study was only powered to detect a difference in the rate of high fever between the two treatment regimens and the sample size was not sufficient to study the efficacy of $600 \mathrm{mcg}$ dose. Furthermore, due to the infrequency of PPH events following routine use of oxytocin prophlaxis during the timeframe of the pilot study, the original calculated sample size of $75 \mathrm{PPH}$ cases was not met. An additional limitation relates to the study design as the results from the $600 \mathrm{mcg}$ dose were compared with historical cohort data from a previous study conducted in Ecuador. The trend towards a reduction in high fevers may have been influenced by other factors, such as the provision of oxytocin prophylactically in the present study, which was not routinely practiced in the study by Winikoff et al. Nevertheless, the participant characteristics were similar between the two studies (Table 2), and the reduction in fever, as well as the temperature curve following administration of $600 \mathrm{mcg}$, is consistent with other studies that have compared misoprostol doses and systematically measured body temperature $[5,17,22]$. The findings from this study may also have limited generalisability, as it is not yet known whether women in other settings (for example, other South American populations) will also experience similar rates of high fever following postpartum administration of sublingual misoprostol in dosages of 600 or $800 \mathrm{mcg}$.

While this study was not designed to evaluate the effectiveness of the $600 \mathrm{mcg}$ dose, we did document outcomes related to treatment success, including time to bleeding cessation, measured blood loss, change in hemoglobin levels measured pre- and post-delivery, and use of additional interventions (Table 2). First-line treatment with $600 \mathrm{mcg}$ sublingual misoprostol alone controlled PPH within 20 minutes for $82 \%$ of women. In comparison, two large multi-country randomized controlled trials testing an $800 \mathrm{mcg}$ regimen of sublingual misoprostol in the presence and absence of oxytocin prophylaxis confirmed rates of efficacy of $89.2 \%$ (363/ $407)$ and $90.2 \%$ (440/488), respectively [1,2]. Direct comparisons of $\mathrm{PPH}$ outcomes from the two Ecuador cohorts show that women bled less and had better hemoglobin levels after administration of $600 \mathrm{mcg}$
Table 2 Participant characteristics and PPH outcomes among Ecuadorian women given PPH treatment with sublingual misoprostol $(600 \mathrm{mcg}$ and $800 \mathrm{mcg}) *$

\begin{tabular}{|c|c|c|}
\hline & $\begin{array}{l}600 \mathrm{mcg} \\
(\mathrm{n}=50)\end{array}$ & $\begin{array}{l}800 \mathrm{mcg} \\
(\mathrm{n}=163)\end{array}$ \\
\hline \multicolumn{3}{|l|}{ Baseline characteristics } \\
\hline Age $(y r)$ mean \pm sd, & $23 \pm 6$ & $24 \pm 6$ \\
\hline Range & $14-41$ & $14-42$ \\
\hline Currently married & $39(78.0)$ & $140(85.3)$ \\
\hline \multicolumn{3}{|l|}{ Level of education } \\
\hline No education & $0(0.0)$ & $0(0.0)$ \\
\hline Primary & $11(22.0)$ & $50(30.7)$ \\
\hline Secondary & $29(58.0)$ & $96(58.9)$ \\
\hline University or higher & $10(20.0)$ & $14(8.6)$ \\
\hline \multicolumn{3}{|l|}{ No. of previous live births } \\
\hline 0 & $27(54.0)$ & $65(39.9)$ \\
\hline $1-3$ & $21(42.0)$ & $86(52.8)$ \\
\hline $4+$ & $2(4.0)$ & $12(7.3)$ \\
\hline Pre-delivery $\mathrm{Hb}$ mean $\pm \mathrm{sd}$ & $13.4 \pm 1.4$ & $13.5 \pm 1.3$ \\
\hline Range & $10.1-18.1$ & $10.3-16.9$ \\
\hline \multicolumn{3}{|l|}{ Gestational age (wk) } \\
\hline Pre-term (less than 37) & $2(4.0)$ & $6(3.7)$ \\
\hline Term (37.0 - 40.9) & $42(84.0)$ & $137(84.0)$ \\
\hline Post-term (41 or more) & $6(12.0)$ & $20(12.3)$ \\
\hline Multiple pregnancy & $0(0)$ & $0(0)$ \\
\hline Known previous PPH & $1(2.0)$ & $8(4.9)$ \\
\hline \multicolumn{3}{|l|}{ Delivery characteristics } \\
\hline Labor induced/augmented & $34(68.0)$ & - \\
\hline Oxytocin given in 3rd stage of labor & $50(100.0)$ & - \\
\hline Controlled cord traction ${ }^{+}$ & $45(90.0)$ & $114(69.9)$ \\
\hline Uterine massage $^{+}$ & $50(100.0)$ & $131(80.4)$ \\
\hline
\end{tabular}

\section{PPH outcomes}

Blood loss $(\mathrm{mL})$ at time of treatment $850(750,1050) \quad 850(750,1000)$ median (IQR)

\begin{tabular}{lll} 
Total blood loss $(\mathrm{mL})$ median $(\mathrm{IQR})^{+}$ & $1000(850,1200)$ & $1150(950,1400)$ \\
Blood loss $\geq 500 \mathrm{~mL}$ post-treatment & $5(10.0)$ & $29(17.8)$ \\
Blood loss $\geq 1000 \mathrm{~mL}$ post-treatment & $0(0.0)$ & $3(6.0)$ \\
Post-treatment $\mathrm{Hb}$ median IQR $\wedge^{+}$ & $10.8(9.9,11.4)$ & $9.9(8.9,11.0)$ \\
$\begin{array}{l}\text { Difference between pre/post } \mathrm{Hb} \\
\text { median IQR } \wedge^{+}\end{array}$ & $2.6(1.4,4.0)$ & $3.5(2.6,4.8)$ \\
Drop in $\mathrm{Hb} \geq 2 \mathrm{~g} /{\mathrm{dL} \wedge^{+}}^{+}$ & $31(63.3)$ & $131(85.6)$ \\
Additional uterotonics & \\
Blood transfusion & $9(18.0)$ & $12(7.4)$ \\
Exploration under anesthesia & $1(2.0)$ & $10(6.1)$ \\
\hline
\end{tabular}

* Values are given as $n(\%)$ unless stated otherwise.

$\wedge$ Post-delivery hemoglobins available for 49 women in the $600 \mathrm{mcg}$ study and 153 women in $800 \mathrm{mcg}$ study.

$+P \leq 0.05$. 
misoprostol (Table 2). Importantly, the outcomes in the present study are likely the result of the package of $\mathrm{PPH}$ care that women received -- a prophylactic regimen of 10 IU oxytocin followed by treatment with $600 \mathrm{mcg}$ sublingual misoprostol vs. treatment alone in the previous study. Routine use of oxytocin during the third stage of labor also significantly reduced the rate of $\mathrm{PPH}$ diagnosis by $75 \%$ in this setting (no prophylaxis: 29\% (325/1624) vs. prophylaxis: $7 \%(50 / 727)$ ); thus reducing the number of women requiring treatment with oxytocics and their exposure to any side effects from these drugs.

Although some evidence suggests that lower doses of misoprostol may have the same effect on the uterus compared with higher doses [17], no large randomized controlled trials have been conducted confirming the efficacy of lower doses for treating PPH. Indeed, a comparative trial of $600 \mathrm{vs} .800 \mathrm{mcg}$ may not be practical due to the large sample size and the financial resources required to confirm non-inferiority of a lower dose. Furthermore, the $82 \%$ rate of effectiveness, defined as blood loss controlled within 20 minutes with misoprostol treatment alone, documented in the present study suggests a possible loss in efficacy with the lower dose -- a tradeoff that may not be acceptable to providers when treating a life-threatening obstetric condition.

\section{Conclusions}

First-line treatment with $600 \mathrm{mcg}$ of sublingual misoprostol, preceded by the intramuscular provision of $10 \mathrm{IU}$ of oxytocin, works well in controlling hemorrhage and minimizing the occurrence of high fever among Ecuadorian women. The lower misoprostol dose offers a potential solution for treating $\mathrm{PPH}$ in communities known to be more susceptible to higher rates of misoprostol's thermoregulatory effects. However, these findings do not provide conclusive evidence of misoprostol's efficacy using this lower dose. Moreover, there is no evidence that this dosage alone in the absence of oxytocin prophylaxis would be an effective intervention for controlling $\mathrm{PPH}$ and avoiding side effects. Until additional information becomes available on the effectiveness of lower dosages, the evidence-based $800 \mathrm{mcg}$ sublingual regimen is recommended, particularly in settings where the provision of intravenous oxytocin is not feasible $[1,2]$. Operations research utilizing the $800 \mathrm{mcg}$ sublingual regimen in other settings is recommended to confirm the safety and acceptability of this approach to manage cases of PPH. If indeed unusually high rates of elevated body temperature are documented among other populations, future research on the efficacy of lower dosages for treating PPH may be justified.

Abbreviation

PPH: Postpartum hemorrhage.
Competing interests

The authors declare that they have no competing interests.

\section{Acknowledgements}

The authors first and foremost thank the women who participated in this study and the hospital staff who attended to them in addition to collecting necessary data for this study in Quito: Catalina Jácome, María Caiza, Sonia Cajas and César Carvajal. We thank Dr. Humberto Navas, Dr. Rolando Montesinos and others authorities of the Maternity Hospital Isidro Ayora in Quito, Ecuador for their support. We also wish to acknowledge our Data Safety and Monitoring Board Members for their time and contributions. The authors also thank Ms. Jennifer Blum for reviewing this manuscript. This research was funded by a grant from the Bill and Melinda Gates Foundation. The Foundation had no role in the actual planning, writing or submission of this paper.

\section{Author details}

${ }^{1}$ Hospital Gineco-Obstétrico Isidro Ayora, Quito, Ecuador. ${ }^{2}$ Gynuity Health Projects, New York, NY, USA.

\section{Authors' contributions}

WL: contributed to the conception of the trial, participated in its implementation and interpretation of the trial findings, and helped draft the manuscript. JD: contributed to the conception of the trial, provided clinical monitoring, analyzed the study findings and drafted the manuscript. GB: participated in the study implementation and interpretation of results. EP: participated in the study implementation, managed the data collected, and participated in the interpretation of result. BW: contributed to the conception of the trial, helped interpret data and draft the manuscript. All authors read and approved the final manuscript.

Received: 16 December 2011 Accepted: 7 July 2012

Published: 7 July 2012

\section{References}

1. Blum J, Winikoff B, Raghavan S, Dabash R, Ramadan MC, Dilbaz B, Dao B, Durocher J, Yalvac S, Diop A, et al: Treatment of post-partum haemorrhage with sublingual misoprostol versus oxytocin in women receiving prophylactic oxytocin: a double-blind, randomised, noninferiority trial. Lancet 2010, 375(9710):217-223.

2. Winikoff B, Dabash R, Durocher J, Darwish E, Nguyen TN, Leon W, Raghavan S, Medhat I, Huynh TK, Barrera G, et al: Treatment of post-partum haemorrhage with sublingual misoprostol versus oxytocin in women not exposed to oxytocin during labour: a double-blind, randomised, noninferiority trial. Lancet 2010, 375(9710):210-216.

3. Hofmeyr GJ, Gulmezoglu AM: Misoprostol for the prevention and treatment of postpartum haemorrhage. Best Pract Res Clin Obstet Gynaecol 2008, 22(6):1025-1041.

4. Lumbiganon P, Hofmeyr J, Gulmezoglu AM, Pinol A, Villar J: Misoprostol dose-related shivering and pyrexia in the third stage of labour. WHO Collaborative Trial of Misoprostol in the Management of the Third Stage of Labour. Br J Obstet Gynaecol 1999, 106(4):304-308.

5. Khan R-U, El-Refaey H: Pharmacokinetics and Adverse-Effect Profile of Rectally Administered Misoprostol in the Third Stage of Labor. Obstet Gynecol 2003, 101(5):968-974.

6. Chong YS, Chua S, Shen L, Arulkumaran S: Does the route of administration of misoprostol make a difference? The uterotonic effect and side effects of misoprostol given by different routes after vaginal delivery. Eur J Obstet Gynecol Reprod Biol 2004, 113(2):191-198.

7. Tang OS, Gemzell-Danielsson K, Ho PC: Misoprostol: pharmacokinetic profiles, effects on the uterus and side-effects. Int J Gynaecol Obstet 2007, 99(Suppl 2):S160-167.

8. Chong YS, Chua S, Arulkumaran S: Severe hyperthermia following oral misoprostol in the immediate postpartum period. Obstet Gynecol 1997, 90(4 Pt 2):703-704.

9. Gulmezoglu AM, Villar J, Ngoc NT, Piaggio G, Carroli G, Adetoro L, Abdel-Aleem H, Cheng L, Hofmeyr G, Lumbiganon P, et al: WHO multicentre randomised trial of misoprostol in the management of the third stage of labour. Lancet 2001, 358(9283):689-695. 
10. Ng PS, Chan AS, Sin WK, Tang LC, Cheung KB, Yuen PM: A multicentre randomized controlled trial of oral misoprostol and i.m. syntometrine in the management of the third stage of labour. Hum Reprod 2001, 16(1):31-35.

11. Hofmeyr GJ, Ferreira S, Nikodem VC, Mangesi L, Singata M, Jaffa Z, Maholwana B, Mlokoti Z, Walraven G, Gülmezoglu AM: Misoprostol for treating postpartum haemorrhage: a randomized controlled trial [ISRCTN72263357]. BioMed Central Pregnancy and Childbirth 2004, 4(16):1-7.

12. Zuberi NF, Durocher J, Sikander R, Baber N, Blum J, Walraven G: Misoprostol in addition to routine treatment of postpartum hemorrhage: a hospitalbased randomized-controlled trial in Karachi. Pakistan. BMC Pregnancy Childbirth 2008, 8:40.

13. Widmer M, Blum J, Hofmeyr GJ, Carroli G, Abdel-Aleem H, Lumbiganon P, Nguyen TN, Wojdyla D, Thinkhamrop J, Singata M, et al: Misoprostol as an adjunct to standard uterotonics for treatment of post-partum haemorrhage: a multicentre, double-blind randomised trial. Lancet 2010 375(9728):1808-1813.

14. Durocher J, Bynum J, Leon W, Barrera G, Winikoff B: High fever following postpartum administration of sublingual misoprostol. Bjog 2010, 117 (7):845-852.

15. Alfirevic Z, Blum J, Walraven G, Weeks A, Winikoff B: Prevention of postpartum hemorrhage with misoprostol. International Journal of Gynaecology and Obstetrics 2007, 99(Supplement 2):S198-201.

16. Soltan MH, El-Gendi E, Imam HH, Fathi O: Different Doses of Sublingual Misoprostol versus Methylergometrine for the Prevention of Atonic Postpartum Haemorrhage. Int J Health Sci (Qassim) 2007, 1(2):229-236.

17. Elati A, Elmahaishi MS, Elmahaishi MO, Elsraiti OA, Weeks AD: The effect of misoprostol on postpartum contractions: a randomised comparison of three sublingual doses. BJOG 2011, 118(4):466-473.

18. Lam H, Tang OS, Lee CP, Ho PC: A pilot-randomized comparison of sublingual misoprostol with syntometrine on the blood loss in third stage of labor. Acta Obstetricia et Gynecologica Scandinavica 2004, 83 (7):647-650.

19. Høj L, Cardoso P, Nielsen BB, Hvidman L, Nielsen J, Aaby P: Effect of sublingual misoprostol on severe postpartum haemorrhage in a primary health centre in Guinea-Bissau: randomised double blind clinical trial. BMJ: British Medical Journal 2005, 331(7519):723-727.

20. Al-Harazi AH, Frass KA: Sublingual misoprostol for the prevention of postpartum hemorrhage. Saudi Med J 2009, 30(7):912-916.

21. Singh G, Radhakrishnan G, Guleria K: Comparison of sublingual misoprostol, intravenous oxytocin, and intravenous methylergometrine in active management of the third stage of labor. International Journal of Gynecology \& Obstetrics 2009, 107(2):130.

22. Lumbiganon P, Villar J, Piaggio G, Gulmezoglu AM, Adetoro L, Carroli G: Side effects of oral misoprostol during the first 24 hours after administration in the third stage of labour. British Journal of Obstetrics and Gynaecology 2002, 109(11):1222-1226.

doi:10.1186/1471-2393-12-65

Cite this article as: León et al:: Dose and side effects of sublingual misoprostol for treatment of postpartum hemorrhage: what difference do they make?. BMC Pregnancy and Childbirth 2012 12:65.

\section{Submit your next manuscript to BioMed Central and take full advantage of:}

- Convenient online submission

- Thorough peer review

- No space constraints or color figure charges

- Immediate publication on acceptance

- Inclusion in PubMed, CAS, Scopus and Google Scholar

- Research which is freely available for redistribution

Submit your manuscript at www.biomedcentral.com/submit 